\title{
Bending and Shear Experimental Tests and Numerical Analysis of Composite Slabs Made Up of Lightweight Concrete
}

\author{
F. P. Alvarez Rabanal, ${ }^{1}$ J. Guerrero-Muñoz, ${ }^{2}$ \\ M. Alonso-Martinez, ${ }^{1}$ and J. E. Martinez-Martinez ${ }^{1}$ \\ ${ }^{1}$ Construction and Manufacturing Department, University of Oviedo, Gijón, Spain \\ ${ }^{2}$ Advanced Simulation Technologies, S.L. Parque Científico Tecnológico de Gijón, Gijón, Spain \\ Correspondence should be addressed to M. Alonso-Martinez; mar@constru.uniovi.es
}

Received 23 September 2016; Accepted 23 November 2016

Academic Editor: Peng Zhang

Copyright (C) 2016 F. P. Alvarez Rabanal et al. This is an open access article distributed under the Creative Commons Attribution License, which permits unrestricted use, distribution, and reproduction in any medium, provided the original work is properly cited.

The aim of this paper is to understand the structural behaviour of composite slabs. These composite slabs are made of steel and different kinds of concrete. The methodology used in this paper combines experimental studies with advanced techniques of numerical simulations. In this paper, four types of concrete were used in order to study their different structural strengths in composite slabs. The materials used were three lightweight concretes, a normal concrete, and a cold conformed steel deck which has embossments to increase the adherence between concrete and steel. Furthermore, two lengths of slabs were studied to compare structural behaviours between short and long slabs. $m$ - $k$ experimental tests were carried out to obtain the flexural behaviour of the composite slabs. These tests provide dimensionless coefficients to compare different sizes of slabs. Nonlinear numerical simulations were performed by means of the finite element method (FEM). Four different multilinear isotropic hardening laws were used to simulate the four concretes. Coulomb friction contact was used to model the coefficient of friction between steel and concrete. Finally, a chemical bond was included to consider sliding resistance in the contact surface between steel and concrete. Experimental and numerical results are in good agreement; therefore, numerical models can be used to improve and optimize lightweight composite slabs.

\section{Introduction}

Composite slabs are made up of a thin steel sheet and concrete. Reinforced bars are often needed inside the composite layer in order to reduce shrinkage as well as avoid/prevent bending stress [1]. Stress analysis of composite slabs shall consider two phases:

(i) Implementation phase, in which the steel sheet works as a framework. In this phase, the steel sheet must withstand transmitted loads of fresh concrete.

(ii) Service phase, in which concrete and steel work together to support stress. Efficiency of the composite slab depends on the interaction between the concrete layer and the steel sheet.

In this paper, new composite slabs made up of steel deck and lightweight concrete are studied. Composite slabs are efficient and versatile elements [2,3], but the advantages of composite slabs made of lightweight concrete (LWC) and steel make them especially suitable for industrial applications [4].

Firstly, composite slabs made of LWC and steel are very efficient due to the combination of these two materials, steel and concrete. The tensile strength of steel and the compressive strength of concrete provide increased slab stiffness. Secondly, the weight of these composite slabs is reduced due to the use of lightweight concrete. This advantage makes transport and storage easier, as well as reducing foundation size. Thirdly, these composite slabs are manufactured in an industrialized process and a higher quality is achieved. Furthermore, the construction process with precast concrete is easier and faster. Fourthly, the materials used are recyclable. This enhances the product life and makes the use of composite slabs a sustainable process. Finally, composite slabs made of lightweight concrete are more economical than traditional 


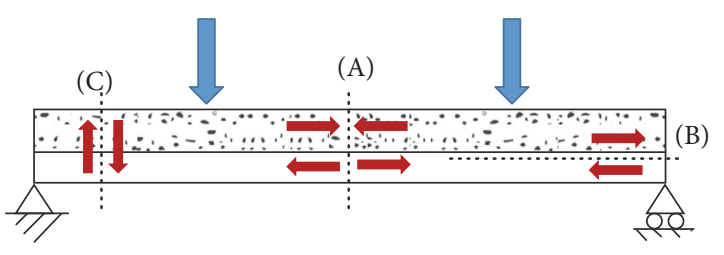

(A): Sagging moment failure mode

(B): Longitudinal shear failure mode

(C): Vertical shear failure mode

Figure 1: Failure modes of composite slabs.

slabs. They use less concrete, do not require an auxiliary framework, and reduce the weight of the structure, among other benefits.

Structural analysis of composite slabs is based on their failure modes. The main failure modes of composite slabs are due to bending stress and longitudinal displacement:

(i) Failure mode due to "sagging moment" which is related to the bending resistance of the composite slab, Figure 1(A).

(ii) Failure mode of "longitudinal shear" because the contact between steel and concrete reaches the ultimate shear load resistance, Figure 1(B).

Sagging moment is usually the main failure mode of large and thin slabs where shear stress is low compared to bending stress. Vertical shear stress is usually lower than the others, so it is rarely the main failure mode.

In order to study the structural behaviour of composite slabs, the connection between steel and concrete must be studied. Chemical adhesion has been studied by other authors through $m$ - $k$ tests [6].

The stress transfer between LWC and steel depends on both mechanical and frictional interaction. The resistance of this contact is obtained by $m-k$ tests which are specified in Eurocode 4 [5]. Shear stress of composite slabs can be determined by this European Standard. However, theoretical prediction of composite slabs is very difficult because it depends on many variables, such as the geometry of steel deck and embossments.

$m-k$ tests determine relative displacement between the steel sheet and the concrete when shear stress is applied to the composite slab. In this test, a cyclic load is applied in order to take into account the whole life cycle of the composite slabs before collapse. The application of this cyclic load is required to break the chemical bond between the steel and the LWC. In this way, other failure modes in the slabs can be identified.

Other authors have studied the efficiency of $m-k$ tests to determine the bending behaviour of composite slabs $[1-4,6$, 7]. These studies identify important considerations to achieve successful results in $m-k$ tests, such as the introduction of crack initiators in concrete, the influence of the thickness of the steel sheet, or the influence of cyclic preloads applied. The conclusions reveal a reduction in strength due to crack initiators. However, current standards take them into account because they contribute to the control of the slab breakage.
The results show the low influence of the chemical bond between concrete and steel, while embossments, coefficient of friction, and mechanical connectors guarantee suitable interaction between concrete and steel.

$m-k$ experimental tests are based on four point bending tests. The main results show the ductile behaviour of concrete as well as a $20 \%$ of weight reduction. However, some disadvantages are presented such as a reduction of the strength capacity due to the use of LWC instead of normal concrete $[8,9]$.

The original contribution of this paper is the study of the structural behaviour of composite slabs made of structural lightweight concrete instead of normal concrete. Furthermore, this LWC is reinforced with polyolefin fibres in order to reduce shrinkage stress.

\section{Materials and Methods}

2.1. Materials. Initially, lightweight aggregates were obtained from natural resources, mainly of volcanic origin: pumice, slag, volcanic tuff, and so forth. The lack of natural resources and the increment in the demand for lightweight aggregates made industrial processes to manufacture aggregates necessary. These aggregates include expanded clay, schist, and slate, as well as industrial byproducts such as fly ash and dust from blast furnace. The properties of these aggregates depend on the raw materials and the manufacturing processes.

Lightweight aggregates of different densities can be manufactured ranging from $50 \mathrm{~kg} / \mathrm{m}^{3}$ for expanded perlite to $1000 \mathrm{~kg} / \mathrm{m}^{3}$ for clinker. The compressive strength obtained for LWCs can be increased up to $80 \mathrm{MPa}$ for cubic specimens with the addition of these aggregates and high-effect additives which reduce the amount of water required. The low density of this material provides high thermal insulation in buildings, up to 6 times higher than normal concrete [10].

In this paper, the aggregate used is an expanded clay called "arlite." The main properties of this material are good insulation, porosity, and resistance. Arlite is usually employed to manufacture high-performance ultralight mortars. In order to compare the differences between LWC and normal concrete, four different types of concrete have been studied. Three of them are LWCs made of arlite with different densities and the fourth is normal concrete. These materials are henceforth referred to in the paper as

(i) Normal concrete (HN)

(ii) Structural lightweight concrete type 23 (LWC_LSDur23)

(iii) Structural lightweight concrete type-28 (LWC_LSDur28)

(iv) Structural lightweight concrete type-37 (LWC_LSDur37).

The properties of these materials are included in Table 1 and have been determined following the National Standards UNE-EN 12390-3 [11] and UNE-EN 12390-13 [12].

The Spanish Standard for composite slabs made of steel deck and structural concrete is the Eurocode 4 [5]. This 
TABLE 1: Mechanical properties of studied concrete.

\begin{tabular}{lccc}
\hline Concrete type & Density & $\begin{array}{c}\text { Compressive } \\
\text { strength }(\mathrm{MPa})\end{array}$ & $\begin{array}{c}\text { Young's } \\
\text { modulus } \\
(\mathrm{MPa})\end{array}$ \\
\hline LWC_LSDur-23 & 1875 & 25,60 & $2,07 \cdot 10^{4}$ \\
LWC_LSDur-28 & 1902 & 28,59 & $2,16 \cdot 10^{4}$ \\
LWC_LSDur-37 & 2010 & 30,22 & $2,72 \cdot 10^{4}$ \\
HN & 2435 & 36,97 & $4,57 \cdot 10^{4}$ \\
\hline
\end{tabular}

TABLE 2: Mechanical properties of the ribbed steel sheet obtained in tensile tests.

\begin{tabular}{lcccc}
\hline & 1 & 2 & 3 & Average \\
\hline Elastic modulus (MPa) & 268 & 275 & 271 & 271.33 \\
Young's modulus (GPa) & 206 & 204 & 210 & 208 \\
Poisson coefficient & 0.31 & 0.33 & 0.31 & 0.31 \\
\hline
\end{tabular}

standard is based on the repealed British Standard BS5950, as well as other previous standards regarding service analysis, brittleness, and ductility.

To determine the properties of the steel used, tensile tests on 3 specimens of the same material were developed following the National Standard (UNE-EN-ISO-6892-1) [13]. The results obtained are shown in Table 2.

From the average of the experimental results, the curve engineering stress-strain is obtained. Then, true stress-strain is obtained as shown in Figure 2.

2.2. Experimental Tests. The $m-k$ test measures the maximum load that a composite slab is able to withstand before breakage occurs because of shear stress between the concrete and the steel sheet. Shear failure causes relative sliding between steel and concrete so that the two elements do not work together any longer.

The load applied in this test is a distributed load in two lines located $L / 4$ from the ends of the composite slabs (see Figure 3). After applying the load incrementally, slab longitudinal shear or sagging moment failure occurs.

The test procedure is as follows:

(i) Firstly, the composite slab is weighted until breakage to obtain the maximum fracture load.

(ii) Secondly, a cyclic load ranging from $20 \%$ to $60 \%$ of the maximum fracture load is applied for 5000 cycles.

(iii) Finally, a continuous and ever-increasing load is applied until the slab breaks. The total time of the $m-k$ test must be longer than 3600 seconds. In this test, the ultimate load $\left(W_{t}\right)$ is obtained, as well as the vertical displacement of the center of the slab $(f)$ and the sliding between concrete and steel $(d L)$.

A total of 16 tests were carried out: four types of concrete were studied, three LWCs and the fourth NC, for two different lengths of slabs, $2610 \times 1120 \times 160 \mathrm{~mm}$ and $2030 \times 1120 \times$ $160 \mathrm{~mm}$.

Displacement transducers were used to measure the relative displacement between concrete and steel and also

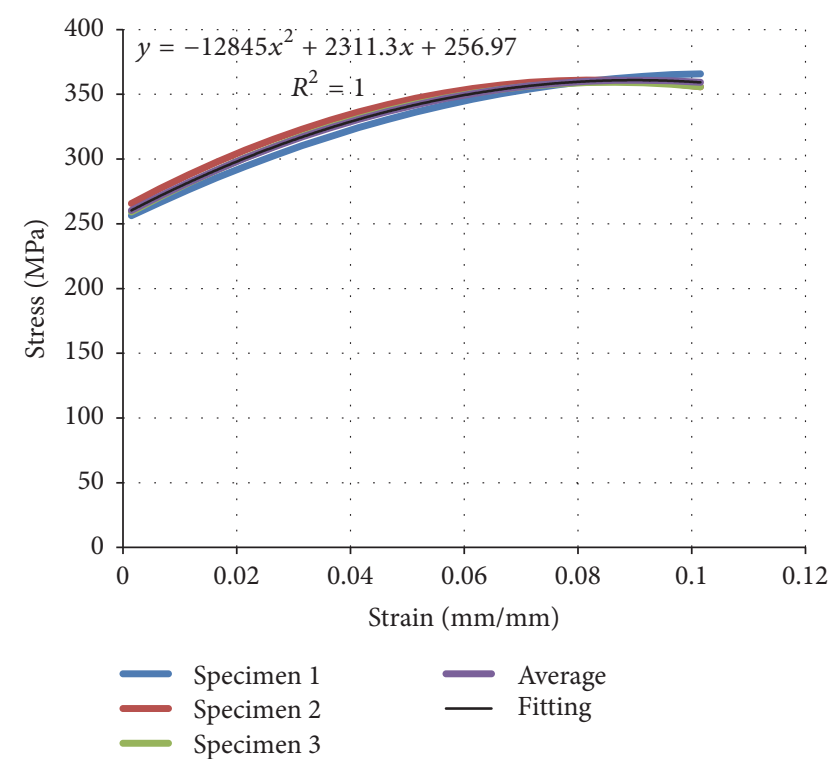

(a) Engineering stress-strain curve

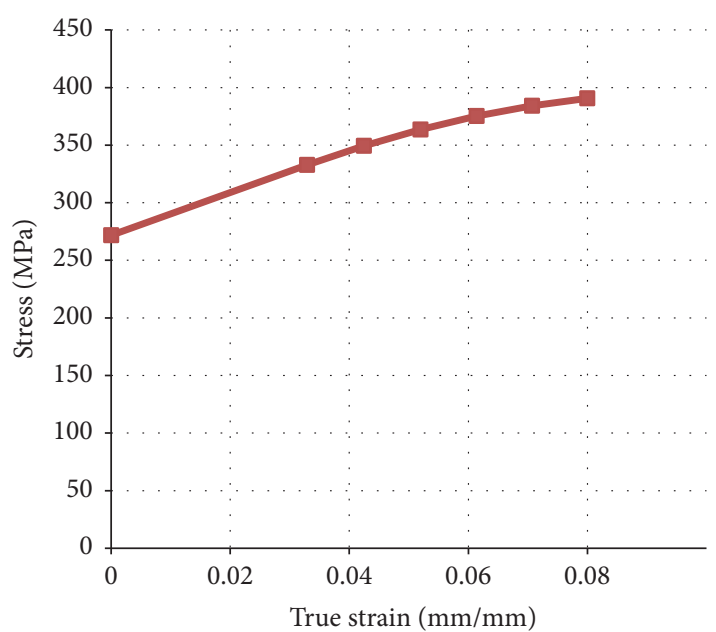

(b) True stress-strain curve

FIGURE 2: Engineering and true stress-strain curves.

the deflection of the slab. Furthermore, the load applied was recorded. Thus, the graphs "load-deflection" and "load-slip" for each slab tested were obtained. $m-k$ coefficients provided slab strength [5, Annex B].

Once the $m-k$ coefficients are calculated, the shear strength for any geometry of each slab type can be obtained using the following equation:

$$
V_{c}=\frac{b \cdot d_{p} \cdot\left[m\left(A_{p} /\left(b \cdot L_{s}\right)\right)+k\right]}{\gamma_{v}},
$$

where $V_{c}$ : is the shear resistance $(\mathrm{N}) . b$ is the width of slab $(\mathrm{mm}) . d_{p}$ is the distance between the centroidal axis of the steel sheeting and the extreme fibre of the composite slab in compression (mm). $m, k$ are design values for the empirical factors obtained from slab tests meeting the basic requirements of the $m-k$ method $\left(\mathrm{N} / \mathrm{mm}^{2}\right) . A_{p}$ is the nominal 


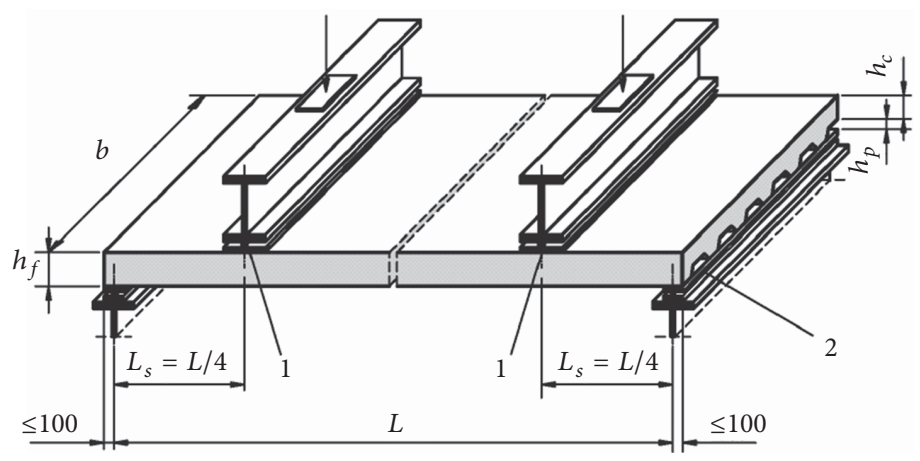

FIGURE 3: $m-k$ test configuration [5, Annex B]. "1" refers to a neoprene support. " 2 " refers to a steel plate support.

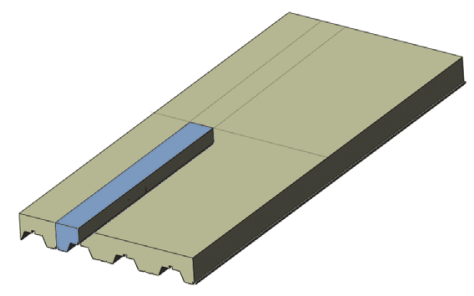

Figure 4: Composite slab geometry for $m-k$ test. Detail of modelled geometry (in blue).

TABLE 3: Finite element mesh properties.

\begin{tabular}{lccc}
\hline $\begin{array}{l}\text { Composite } \\
\text { slab } \\
\text { length }(\mathrm{mm})\end{array}$ & $\begin{array}{c}\text { Number of } \\
\text { elements }\end{array}$ & $\begin{array}{c}\text { Number of } \\
\text { nodes }\end{array}$ & Mesh quality \\
\hline 2030 & 286451 & 261619 & 0.87 \\
2610 & 362945 & 335258 & 0.83 \\
\hline
\end{tabular}

cross section of the sheeting $\left(\mathrm{mm}^{2}\right) . L_{s}$ is the shear span defined in Figure $3(\mathrm{~mm}) \cdot \gamma_{v}$ is the partial safety factor for the ultimate limit state [5].

The results obtained regarding shear resistance depend on the length of the slab; see Table 4 .

2.3. Numerical Analysis. Two different FEA models were built, both for short $(2030 \mathrm{~mm})$ and long $(2610 \mathrm{~mm})$ composite slabs. In order to reduce computational costs, a simplified model was used, corresponding to 1/16 of the geometry of the slab, applying symmetry boundary conditions on the cutting planes (see Figure 4).

The steel deck was modelled using 4-node shell elements (SHELL181), while 8-node solid elements (SOLID185) were used to model the concrete slab (see Figure 5(a)) [14]. The mesh density was increased in the contact area between both materials (see Figure 5(b)). The main features of the mesh used for each model are included in Table 3.

The following boundary conditions were applied:

(1) Symmetry boundary conditions at the model cutting planes (see Figure 6(a)).

(2) Vertical displacement constrained $(\mathrm{UY}=0)$ at support (see Figure 6(b)).
TABLE 4: Values of equivalent shear stress obtained in pull-out tests.

\begin{tabular}{lc}
\hline Concrete type & $\tau_{d}(\mathrm{MPa})$ \\
\hline LWC_LSDur-23 & 0.106 \\
LWC _LSDur-28 & 0.124 \\
LWC _LSDur-37 & 0.162 \\
HN & 0.243 \\
\hline
\end{tabular}

TABLE 5: Summary of load steps introduced in the FEA model.

\begin{tabular}{lccc}
\hline & Load step 1 & Load step 2 & Load step 3 \\
\hline Time step (s) & $2 \times 10^{-5}$ & $1 \times 10^{-3}$ & $1 \times 10^{-3}$ \\
Max. time (s) & 0.1 & 0.1 & 0.1 \\
Force convergence (\%) & 2 & Default & Default \\
\hline
\end{tabular}

(3) Load applied incrementally as displacement at the top surface of the slab (see Figure 6(a)).

The simulations carried out were gradually increased in complexity until achieving good agreement with the empirical results. Specifically, the material laws of both steel and concrete were modified to produce more realistic results, from simple to complex: Initially, linear-elastic material models were used to characterize their behaviour. In a second step, strain-hardening material models were used, with better results than the former. Finally, and initial chemical bond (adhesion) between steel and concrete was also introduced, which produced the best correlation with the test results. The configuration of the load steps in the FEA model are shown in Table 5.

The numerical model takes into account the plastic behaviour of both steel and concrete, using multilinear isotropic hardening laws. The stress-strain data is required to implement the materials models. Steel strength was obtained from tensile tests of 3 specimens from the steel deck, as mentioned in Section 2.1 (see Table 1). The stress-strain data for the different types of concrete are determined using the formulae provided in articles 15 (materials) and 39 (characteristics of concrete) from the Spanish code EHE [15], adjusting the curves with the results obtained experimentally.

$$
f_{c d}=\alpha_{c c} \cdot \frac{f_{c k}}{\gamma_{c}}
$$




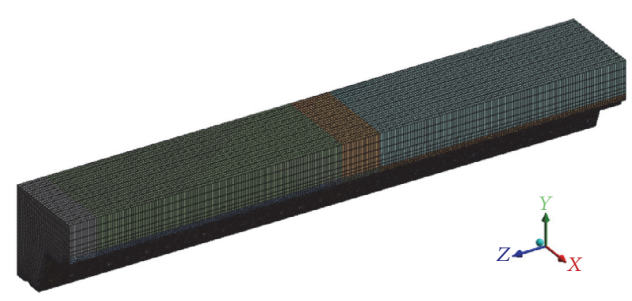

(a)

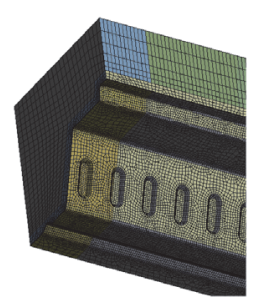

(b)

Figure 5: Composite slab model for $m-k$ test. Mesh detail.

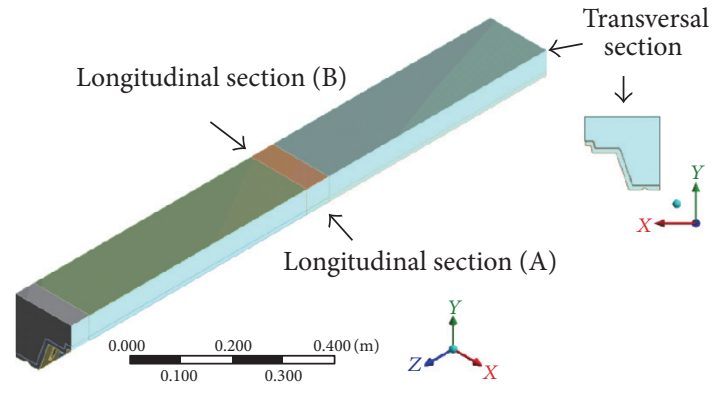

(a)

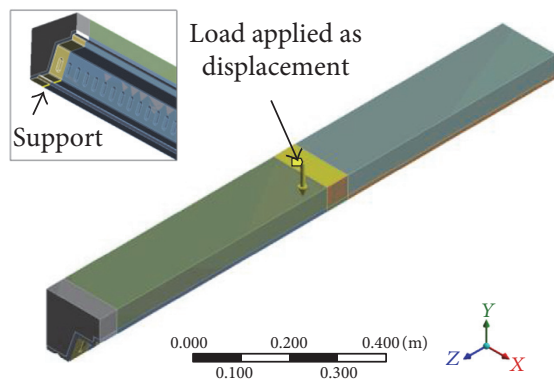

(b)

FIGURE 6: Boundary conditions applied on $m-k$ model.

where $\alpha_{c c}$ is the factor which takes account of the fatigue in the concrete when it is subjected to high levels of compression stress due to long duration loads.. The EHE-08 Standard recommends $0.85 \leq \alpha_{c c} \leq 1 . f_{c k}$ is the characteristic design strength $(\mathrm{MPa}) . \gamma_{c}$ is the safety coefficient for ultimate limit state (ULS). In the case of concrete, $\gamma_{c}=1.5$.

The relation stress-strain can be determined with the following equations [15]:

$$
\begin{aligned}
& \sigma_{m}=f_{c d} \cdot\left[1-\frac{\varepsilon_{m}}{\varepsilon_{c o}}\right]^{n}+\sigma_{m-1}, \quad \text { If } 0 \leq \varepsilon_{c} \leq \varepsilon_{c o}, \\
& \sigma_{m}=f_{c d}, \quad \text { If } \varepsilon_{c o} \leq \varepsilon_{c} \leq \varepsilon_{c u},
\end{aligned}
$$

where $\sigma_{m}$ is the stress of the point $m$ (in $\mathrm{MPa}$ ). $\varepsilon_{m}$ is the strain of the point $m$ (in $\mathrm{mm} / \mathrm{mm}$ ). $\varepsilon_{c o}$ is the maximum compressive strain in the concrete under simple compression (in $\mathrm{mm} / \mathrm{mm}$ ). $\varepsilon_{c o}=0.002$ if $f_{c k} \leq 50 \mathrm{MPa} . \varepsilon_{c u}$ is the ultimate bending strain (in $\mathrm{mm} / \mathrm{mm}$ ) $\varepsilon_{c u}=0.0035$ if $f_{c k} \leq 50 \mathrm{MPa} . n$ is the exponent of the parabola $n=2$ if $f_{c k} \leq 50 \mathrm{MPa}$.

Following previous equations, stress-strain curves of concrete are included in the numerical simulation (see Figure 7). A multilinear isotropic hardening is included in the numerical model to simulate actual concrete behaviour.

Furthermore, the Coulomb friction contact model was used at the contact areas between concrete and the steel deck. As main characteristics, an asymmetric contact was selected, using a friction coefficient of 0.3 .

Additionally, the chemical bond between steel and concrete was simulated in the model by introducing some sliding resistance. In this way, the contacting surfaces carry shear stresses up to a certain magnitude across their interface before they start sliding relative to each other. The equivalent shear stress $\tau$, at which sliding on the surface begins as a fraction of the contact pressure $p$, is calculated with the following equation:

$$
\tau=\mu p+\mathrm{COHE},
$$

where $\mu$ is the friction coefficient and COHE is the cohesion sliding resistance.

If the pressure applied provides enough shear stress, sliding between concrete and steel starts. The values for the shear stress at which sliding begins $\left(\tau_{d}\right)$ were estimated from the results obtained in pull-out tests carried out on reduced specimens of the composite slabs under study. These were the basis for the posterior adjustment of the models [16].

The analysis was divided into 3 load steps, where the load, applied as a remote displacement, was incremented gradually up to $6 \mathrm{~mm}$ for long slabs and 3-4 $\mathrm{mm}$ for short slabs, using small time steps.

\section{Results and Comparison}

The results of experimental tests and numerical analysis are included in this chapter. Finally, a numerical and experimental comparison is presented in order to validate numerical simulations as well as obtain a good agreement between numerical models and experimental tests.

3.1. Experimental Results. The $m-k$ experimental tests of LWC slabs showed similarities while the HN slabs presented different behaviour.

For composite slabs of LWC, the longitudinal sliding between the steel sheet and the concrete was lower than 


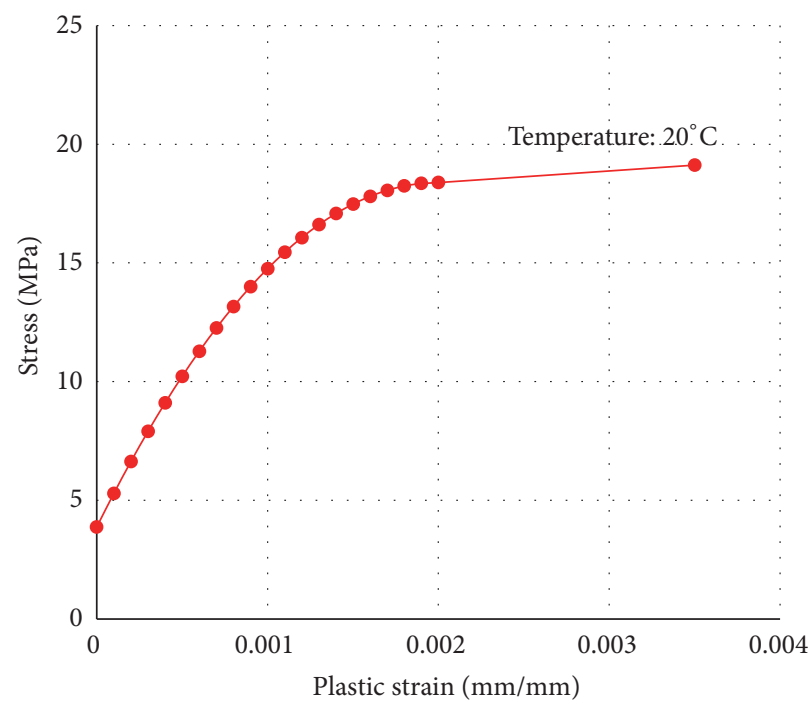

(a)

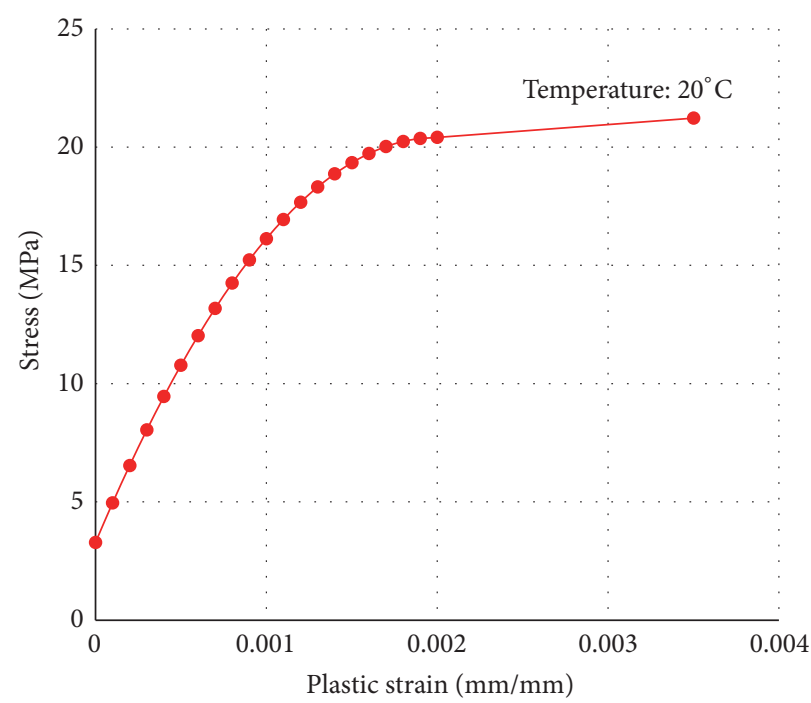

(c)

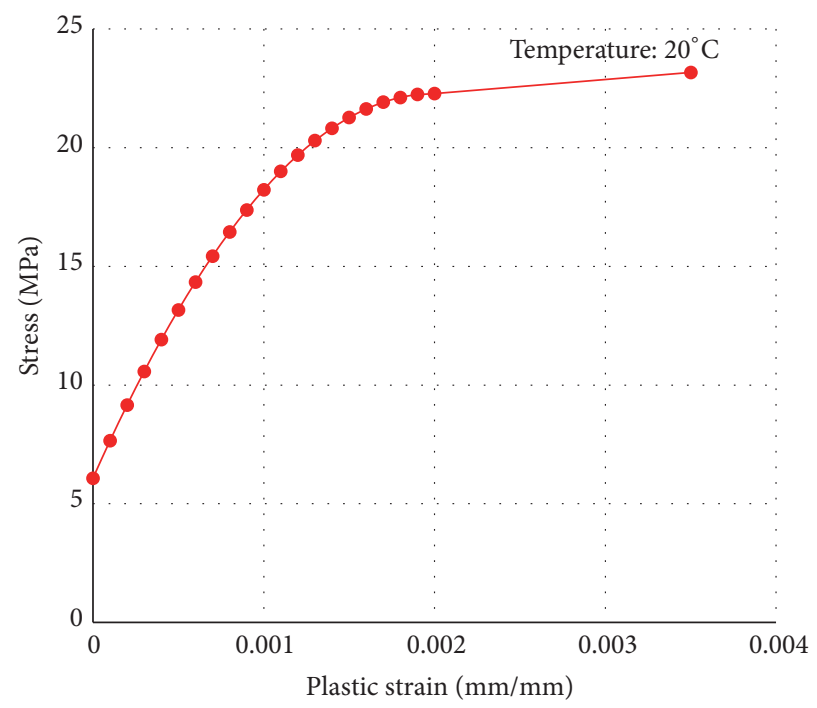

(b)

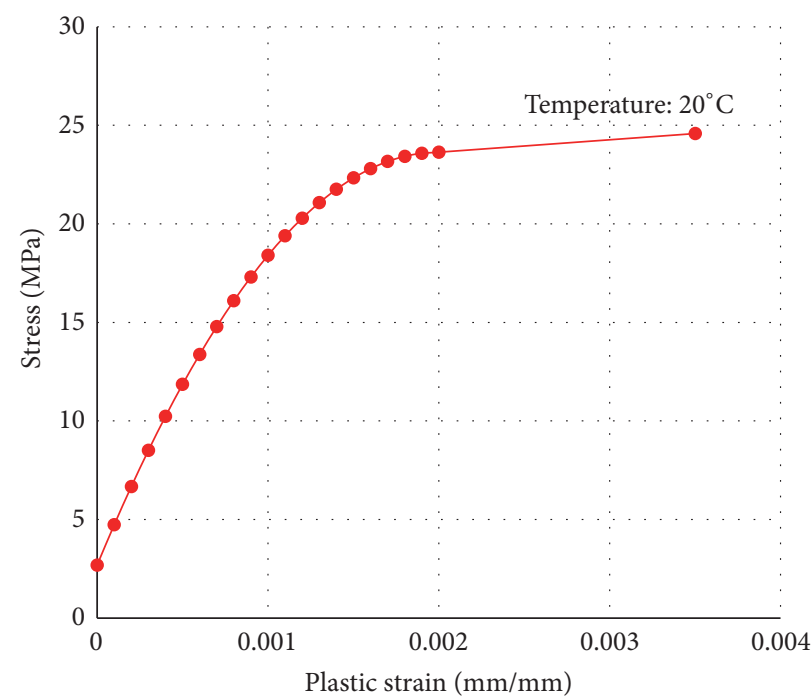

(d)

FIGURE 7: Multilinear isotropic hardening material laws introduced in the models: (a) LWC_LSDur-23, (b) LWC_LSDur-28, (c) LWC_LSDur37 , and (d) normal concrete (HN).

$0.1 \mathrm{~mm}$ when the failure load was reached. In this case, as indicated in the standard, the shear behaviour is considered brittle fracture. This involves that the shear strength is reduced by a coefficient of 0.8 .

This brittle behaviour is often observed in $m-k$ tests of normal concrete composite slabs when the cyclic load applied during the tests does not efficiently remove the chemical bond between steel and concrete. This was considered the cause for the test results of the LWC's composite slabs under study, which was later corroborated by the numerical analysis.

On the other hand, HN composite slabs showed different behaviour. In the case of $\mathrm{HN}$, the measured longitudinal sliding was higher than $0.1 \mathrm{~mm}$ at the failure load, which is considered as ductile fracture.

The results obtained in $m-k$ tests are gathered in Table 6 .
The experimental tests results provide different $m-k$ values for each composite slab. Results are fitted to determine a general equation for each composite slab type. Fitted representations are shown in Figure 8.

The mode of failure of the composite slabs was not a dominant and evident crack (see Figure 9). The majority of the composite slabs showed many small cracks. In the tests, it was considered that the slab failed when a significant increment in longitudinal sliding was measured.

The displacement between the steel sheet and concrete means that the failure of the composite slab is longitudinal shear stress. The length and the thickness of the slabs tested provided this failure mode.

In any case, the longitudinal sliding recorded at the end of the tests was very small for all composite slabs studied and not discernible to the naked eye. 
TABLE 6: $m-k$ tests results.

\begin{tabular}{|c|c|c|c|c|c|c|c|c|}
\hline Concrete type & Length (mm) & $L_{s}(\mathrm{~mm})$ & $W_{t}(\mathrm{kN})$ & $V_{\text {tck }}(\mathrm{kN})$ & $A_{p} / b \cdot L_{s}$ & $V_{s} / b \cdot d_{p}\left(\mathrm{~N} / \mathrm{mm}^{2}\right)$ & $m\left(\mathrm{~N} / \mathrm{mm}^{2}\right)$ & $k\left(\mathrm{~N} / \mathrm{mm}^{2}\right)$ \\
\hline \multirow{2}{*}{ LWC_LSDur-23 } & 2610 & 600 & 133 & 50.57 & 0.0024 & 0.322 & \multirow{2}{*}{112.2} & \multirow{2}{*}{0.0562} \\
\hline & 2030 & 455 & 166 & 63.1 & 0.0031 & 0.402 & & \\
\hline \multirow{2}{*}{ LWC_LSDur-28 } & 2610 & 600 & 148 & 56.27 & 0.0024 & 0.359 & \multirow{2}{*}{68} & \multirow{2}{*}{0.1974} \\
\hline & 2030 & 455 & 168 & 63.87 & 0.0031 & 0.407 & & \\
\hline \multirow{2}{*}{ LWC_LSDur-37 } & 2610 & 600 & 157 & 59.7 & 0.0024 & 0.380 & \multirow{2}{*}{119} & \multirow{2}{*}{0.0982} \\
\hline & 2030 & 455 & 192 & 72.97 & 0.0031 & 0.465 & & \\
\hline \multirow{2}{*}{$\mathrm{HN}$} & 2610 & 600 & 176 & 83.67 & 0.0024 & 0.533 & \multirow{2}{*}{72.25} & \multirow{2}{*}{0.3618} \\
\hline & 2030 & 455 & 193 & 91.7 & 0.0031 & 0.585 & & \\
\hline
\end{tabular}

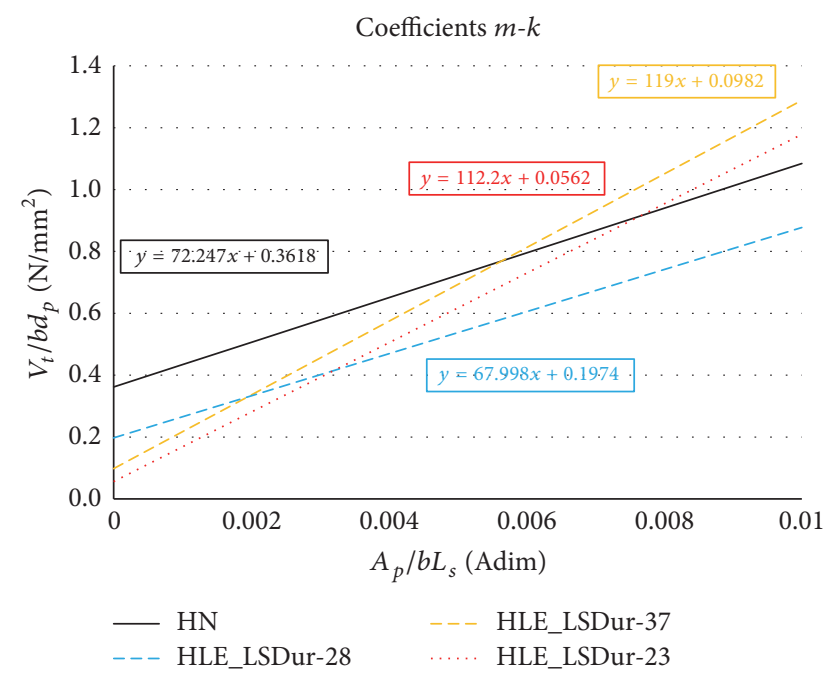

FIGURE 8: $m-k$ curve fitted for composite slabs tested.

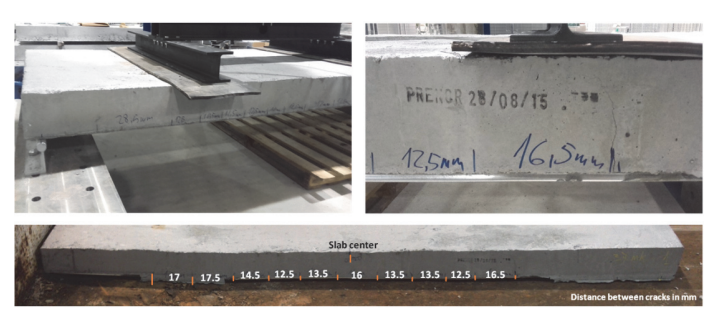

Figure 9: Composite slab LWC_LSDur-37, $2610 \mathrm{~mm}$ long after $m-k$ test.

3.2. Numerical Results. In the numerical model, the vertical displacement applied provides a reaction force similar to the vertical load applied in the experimental test. The numerical model gives stress and deflection results under bending. Figure 10(a) shows the maximum reaction force obtained and Figure 10(b) represents the total deformations calculated.

As mentioned before, in the numerical models, the load (applied as a displacement) was increased gradually until it reached the maximum value observed in the $m-k$ tests.

In order to determine the quality of the numerical results, the values of deflection at the center of the slab obtained by FEA were compared to those measured during testing, for the different simulations carried out.
TABle 7: Plasticity + chemical bond model. Comparison of errors (\%) between numerical and experimental results at the shear-bond failure region.

\begin{tabular}{lcccc}
\hline Concrete type & Length $(\mathrm{mm})$ & $f_{\mathrm{EXP}}(\mathrm{mm})$ & $\begin{array}{c}f_{\mathrm{NUM}} \\
(\mathrm{mm})\end{array}$ & Error $(\%)$ \\
\hline \multirow{2}{*}{ LWC_LSDur-23 } & 2610 & 4.729 & 4.650 & 1.67 \\
& 2030 & 2.666 & 3.262 & 22.36 \\
\hline \multirow{2}{*}{ LWC_LSDur-28 } & 2610 & 4.826 & 4.871 & 0.95 \\
& 2030 & 1.416 & 1.459 & 3.01 \\
\hline \multirow{2}{*}{ LWC_LSDur-37 } & 2610 & 5.906 & 5.718 & 3.18 \\
& 2030 & 1.268 & 1.296 & 2.19 \\
\hline \multirow{2}{*}{ HN } & 2610 & 8.692 & 6.968 & 19.83 \\
& 2030 & 2.066 & 1.886 & 8.72 \\
\hline
\end{tabular}

The results of the linear-elastic material models showed that it was necessary to take into account the plastic behaviour of the concrete to produce more accurate results.

Although the strain-hardening material models without chemical bond provided better results than the previous one, the values of longitudinal sliding between steel and concrete registered in the numerical models were superior to those measured during the tests.

These analysis reinforced the conclusions extracted from the tests regarding the inefficacity of the cyclic loading applied to remove the chemical bond.

Therefore, this chemical bond was finally included into the models, which produced the best correlation with the test results.

3.3. Numerical and Experimental Comparison. In this chapter, the percentages of error (\%) between experimental and numerical analyses are compared.

Firstly, numerical and experimental results are compared with respect to the shear-bond failure region. Table 7 shows the comparison between experimental and numerical results of deflection $f(\mathrm{~mm})$ for the model including plastic behaviour for steel and concrete and the initial adhesion (chemical bond) between both materials.

Except for short span composite slabs made of LSDur23 , the numerical results show good agreement with the experimental results. In case of LSDur-23 slabs, the deviation of the results may be attributed to errors in the water or 


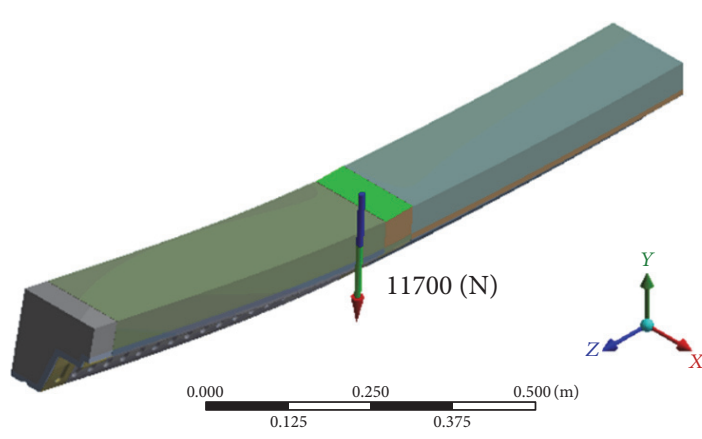

(a)
F: LOSA-2610 mm + + carga

Total deformation

Type: total deformation

Unit: $\mathrm{m}$

0.0024745
0.0022
0.0019256
0.0016511
0.0013767
0.0011022
0.00082779
0.00055334
0.0002789
$4.4476 e-6$

$4.4476 e-6$

(b)

FIGURE 10: Numerical model results: (a) reaction force; (b) total deformation.

TABLE 8: Comparison of errors (\%) of the different models at the shear-bond failure region.

\begin{tabular}{lcccc}
\hline Concrete type & Length $(\mathrm{mm})$ & Linear-elastic model & Plasticity model & Plasticity + chemical bond model \\
\hline \multirow{2}{*}{ LWC_LSDur-23 } & 2610 & 16.28 & 1.18 & 1.67 \\
& 2030 & 0.40 & 23.27 & 22.36 \\
\hline \multirow{2}{*}{ LWC_LSDur-28 } & 2610 & 4.89 & 10.68 & 0.95 \\
& 2030 & 8.51 & 9.69 & 3.01 \\
\multirow{2}{*}{ LWC_LSDur-37 } & 2610 & 34.19 & 4.08 & 3.18 \\
& 2030 & 8.92 & 1.00 & 2.19 \\
\multirow{2}{*}{ HN } & 2610 & 62.22 & 19.25 & 19.83 \\
& 2030 & 45.84 & 12.66 & 8.72 \\
\hline
\end{tabular}

TABLE 9: Comparison of errors (\%) of the different models at the linear-elastic region.

\begin{tabular}{lcccc}
\hline Concrete type & Length $(\mathrm{mm})$ & Linear-elastic model & Plasticity model & Plasticity + chemical bond model \\
\hline \multirow{2}{*}{ LWC_LSDur-23 } & 2610 & 13.54 & 1.61 & 1.97 \\
& 2030 & 9.54 & 15.87 & 14.81 \\
\hline \multirow{2}{*}{ LWC_LSDur-28 } & 2610 & 6.12 & 11.99 & 4.21 \\
& 2030 & 12.86 & 11.90 & 5.65 \\
\multirow{2}{*}{ LWC_LSDur-37 } & 2610 & 19.47 & 0.62 & 3.46 \\
& 2030 & 3.88 & 6.87 & 7.23 \\
\multirow{2}{*}{ HN } & 2610 & 42.30 & 9.48 & 3.57 \\
& 2030 & 38.31 & 21.34 & 9.40 \\
\hline
\end{tabular}

aggregate dosage during the manufacturing of the composite slabs and/or on the displacement measurements taken during the tests.

The results of the linear-elastic model and the plasticity model without adhesion are not shown in detail here but summarized below. The comparison of results at the linearelastic region for all models is also gathered in this section.

From the analysis of the results, it can be concluded that the introduction of the plastic behaviour of the materials is essential to adjust to reality.

In the comparison near the shear-bond failure area (see Table 8), the model including the chemical bond generally shows the best agreement (less than 3.2\% error), except for short slabs dosing LSDur-23 and HN, where the errors obtained are close to $22 \%$. This might suggest that although cyclic loading was applied to the slabs during the test to remove the chemical bond between materials, this bond was not totally eliminated.

In the comparison of the elastic region (see Table 9), the errors in all plasticity models are acceptable, following a similar pattern to the previous comparison; that is, the results for short slabs of LSDur-23 and HN show the worst correlation, although in this case the model fit with chemical adhesion is much better (less than $10 \%$ error).

Finally, the results comparison for the longest span composite slabs $(2610 \mathrm{~mm})$ is shown graphically in Figure 11.

\section{Conclusions}

The main conclusions of this paper are explained in this chapter. 

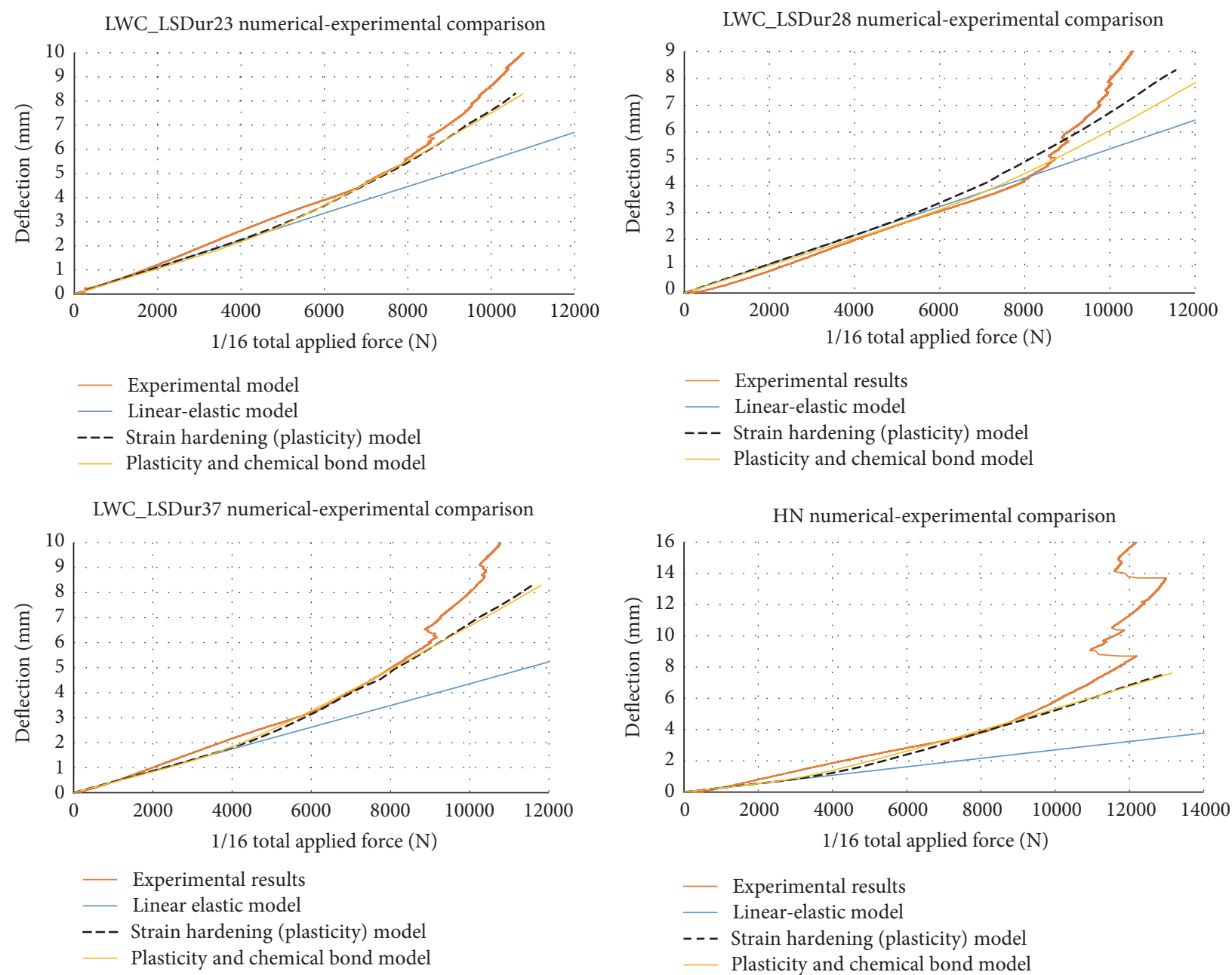

FIGURE 11: Comparison numerical-experimental results for $2610 \mathrm{~mm}$ composite slabs.

Based on the experimental tests, the structural resistance (failure load) of the composite slabs made of lightweight concrete reinforced with fibres is reduced between $11 \%$ and $25 \%$ with respect to conventional concrete, as shown by $m-k$ testing. The main failure mode of composite slabs is longitudinal shear, for both LWC and HN slabs.

With respect to the numerical simulation, the numerical model simulates a 4-point bending test of composite slabs of different lengths according to Eurocode 4. These models were increased in complexity to reproduce the phenomena observed experimentally, introducing frictional contact, chemical adhesion, and plasticity material laws of steel and concrete.

The introduction of plasticity models for the materials is essential to achieve realistic results. In most cases, the plasticity models that include the chemical bond show better correlation with the experimental results. This corroborates the hypothesis that the chemical bond between steel and concrete was only partially removed by the cyclic load applied in the $m-k$ tests.

Although the numerical models developed reproduce the behaviour of specific mixes of LWCs and normal concrete
(4 varieties of concrete, 3 LWCs and one HN), it could also be used for other dosages, provided that their mechanical properties are properly characterized.

Both experimental tests and numerical models show the same failure mode: longitudinal shear. It occurs when the shear strength of the mechanical interlock between concrete and steel is reached and therefore the two layers of the composite slab do not work as a single element.

Finally, it can be concluded that the experimental and numerical results are in good agreement. Moreover, the numerical models developed within this work can be used to improve and optimize the mechanical behaviour of composite slabs.

\section{Competing Interests}

The authors declare that they have no competing interests.

\section{Acknowledgments}

This work was partially financed by the Spanish Ministry of Science and Innovation cofinanced with FEDER funds under 
Research Project BIA2012-31609. Furthermore, the authors are grateful for the regional funding through the Asturias Government and FICYT, also cofinanced with FEDER funds under Research Project FC-15-GRUPIN14- 004.

\section{References}

[1] B. S. Mohammed, M. A. Al-Ganad, and M. Abdullahi, "Analytical and experimental studies on composite slabs utilising palm oil clinker concrete," Construction and Building Materials, vol. 25, no. 8, pp. 3550-3560, 2011.

[2] J. J. Del Coz Díaz, P. J. García Nieto, J. L. Suárez Sierra, and I. Peñuelas Sánchez, "Non-linear thermal optimization and design improvement of a new internal light concrete multiholed brick walls by FEM," Applied Thermal Engineering, vol. 28, no. 8-9, pp. 1090-1100, 2008.

[3] J. J. Del Coz Díaz, P. J. García Nieto, J. Domínguez Hernández, and A. Suárez Sánchez, "Thermal design optimization of lightweight concrete blocks for internal one-way spanning slabs floors by FEM," Energy and Buildings, vol. 41, no. 12, pp. 12761287, 2009.

[4] J. W. Rackham, G. H. Couchman, and S. J. Hicks, "Hicks composite slabs and beams using steel decking: best practice for design and construction," MCRMA Technical Paper 13, Steel Concstruction Institute Publication P300, 2009.

[5] UNE-EN 1994-1-1, EUROCODE 4: Desing of composite steel and concrete structures. Part 1-1: General rules and rules for buildings, 2013.

[6] H. Cifuentes and F. Medina, "Experimental study on shear bond behavior of composite slabs according to Eurocode 4," Journal of Constructional Steel Research, vol. 82, pp. 99-110, 2013.

[7] T. Luu, E. Bortolotti, B. Parmentier, X. Kestemont, M. Briot, and J.-C. Grass, "Experimental investigation of lightweight composite deck slabs," in Proceedings of the 9th International Conference on Steel Concrete Composite and Hybrid Structures, Leeds, UK, July 2009.

[8] A. Penza, Composite slabs with lightweight concrete: experimental evaluation of steel decking and lightweight concrete [Ph.D. thesis], Politecnico di Milano, 2010.

[9] J. Guerrero Muñoz, Analysis and optimization of thermal and structural behavior of composite slabs made of lightweight concrete [Ph.D. thesis], University of Oviedo, 2016.

[10] S. Chandra and L. Berntsson, Lightweight Aggregate Concrete, Noyes Publications, 2002.

[11] UNE, "Testing hardened concrete-part 3: compressive strength of test specimens," UNE-EN 12390-3:2009, 2009.

[12] UNE-EN 12390-13, Testing hardened concrete-Part 13: Determination of secant modulus of elasticity in compression, 2014.

[13] ISO 6892-1, Metallic materials-Tensile testing-Part 1: Method of test at room temperature, 2009.

[14] S. Moaveni, Finite Element Analysis: Theory and Applications with ANSYS, Prentice-Hall, New York, NY, USA, 2007.

[15] EHE 2008 Structural Concrete Instruction, Annex 16, Recommendations for the use of Lightweight Concrete.

[16] B. J. Daniels, "Shear bond pull-out tests for cold-formed-steel composite slabs," Rapport d'Essais ICOM-194, EPFL, Lausanne, Switzerland, 1988. 


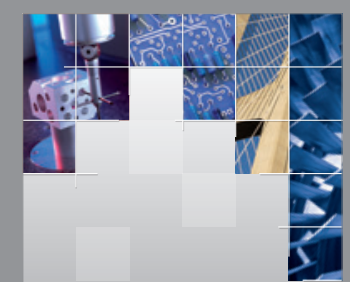

\section{Enfincering}
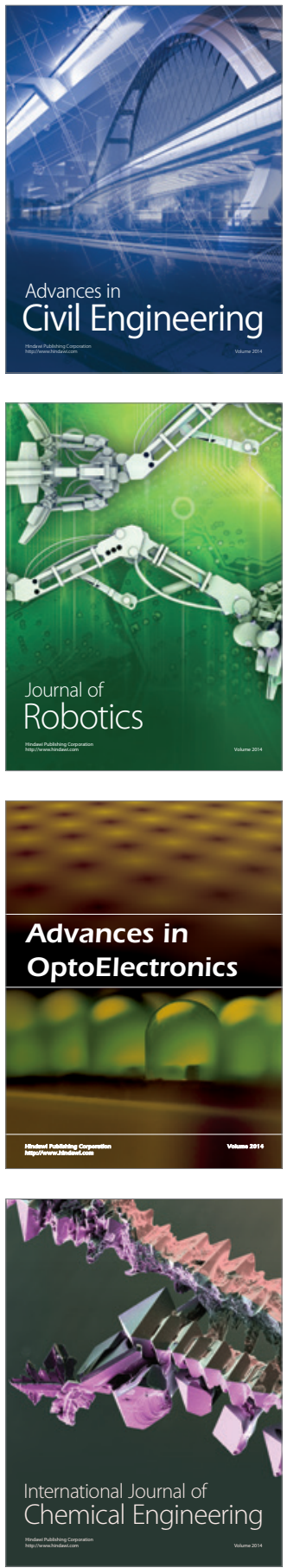

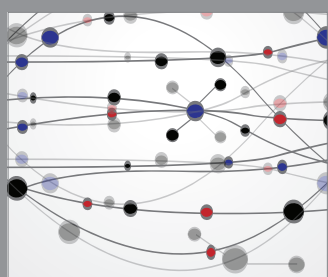

The Scientific World Journal

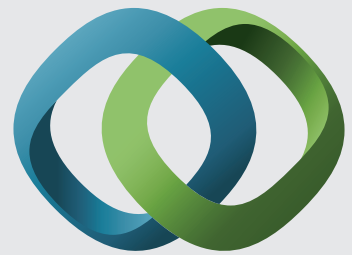

\section{Hindawi}

Submit your manuscripts at

http://www.hindawi.com
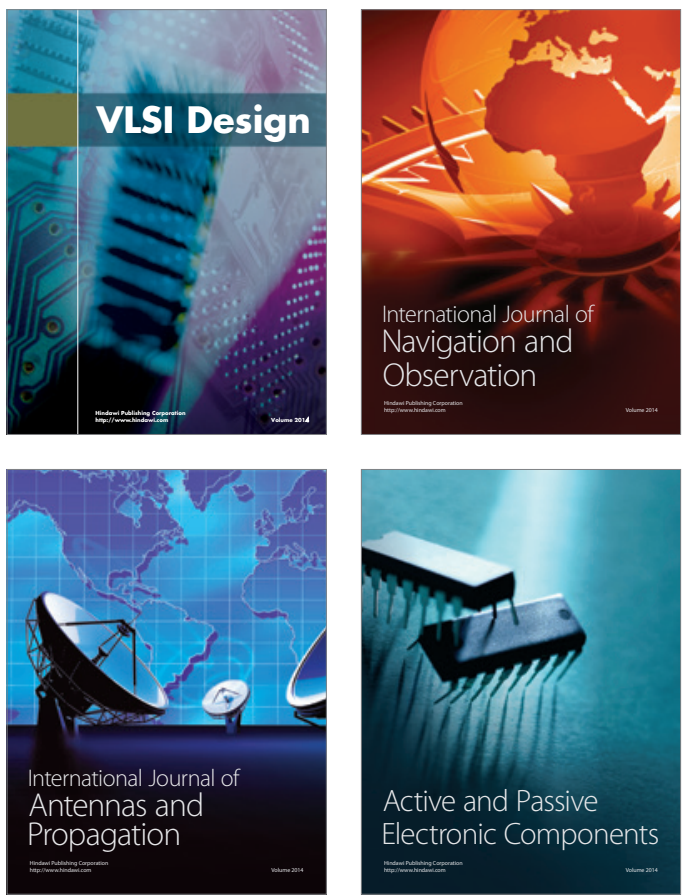
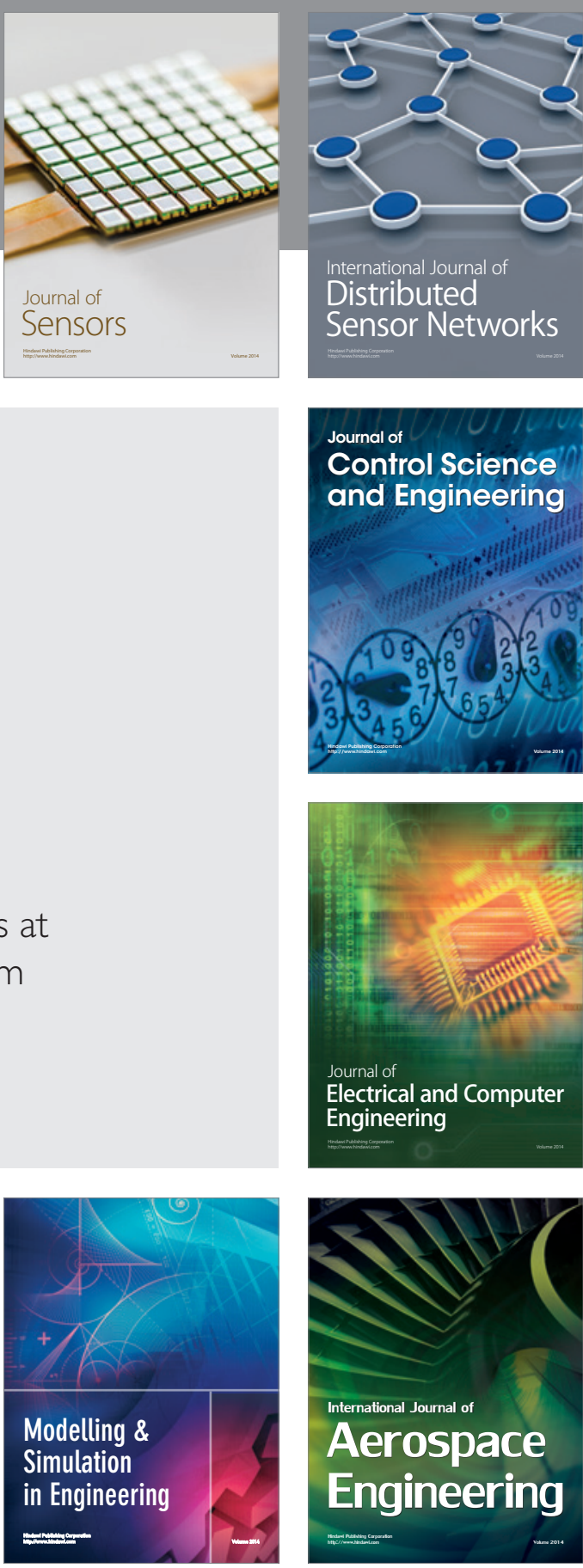

International Journal of

Distributed

Sensor Networks

Journal of

Control Science

and Engineering
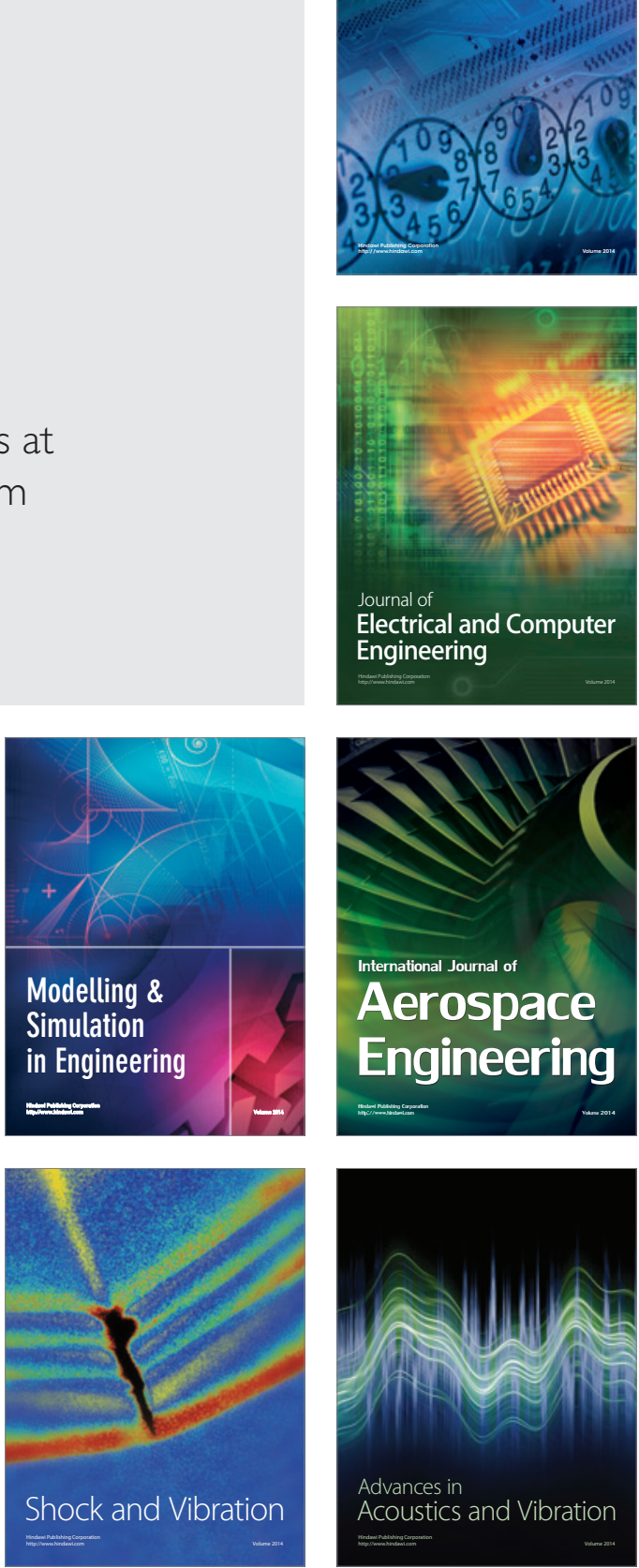